\title{
Monitoring of hospital acquired pneumonia in patients with severe brain injury on first access to intensive neurological rehabilitation: First year of observation
}

\author{
Gianfranco Beghi1, Antonio De Tanti2, Paolo Serafini3, Chiara Bertolino², \\ Antonietta Celentano3, Graziella Taormina² \\ 1 Specialist Pulmonology Rehabilitation Unit, Santo Stefano Institute, Casorate Primo, A.S.S.T. Pavia \\ 2 Cardinal Ferrari Centre, Fontanellato (PR) \\ 3 Santo Stefano Rehabilitation Institute, Porto Potenza Picena (MC), Italy
}

\begin{abstract}
Nosocomial or hospital acquired pneumonia (HAP) is an illness contracted during a hospital stay, generally with onset 48 hours or more after admission to hospital, or within 14 days of discharge from hospital. HAP is divided into subgroups: Ventilator-associated pneumonia (VAP), accounting for $86 \%$ of hospital acquired pneumonia, and strokeassociated pneumonia (SAP). The incidence of SAP in neurological intensive care units (NICUs) is 4.1-56.6\%, in medical intensive care units (MICUs) it is $17-50 \%$, in stroke units it is $3.9-44 \%$ and in rehabilitation it is $3.2-11 \%$, whereas in intensive rehabilitation following severe cranial trauma, the reported incidence of HAP is between 3.9 and $12 \%$ of cases. The aim of this study is to evaluate the cases of HAP occurring in a continuous series of patients with severe acquired brain injury (sABI) admitted to intensive rehabilitation units. The data collected can help evaluate the growing complexity of early rehabilitation of these patients, starting from how lung infections interfere with hospital stays and rehabilitation outcomes.

This prospective observational cohort study evaluates, from 01/01/2015 to $31 / 12 / 2015$, for patients with sABI on first admission to intensive neurological rehabilitation, the frequency of HAP and its impact on patient outcomes and complexity of care. A total of 61 patients were enrolled: 39 males and 22 females, average age 59.5 years (17-88 yrs, SD 3.53), coming from critical care $(n=52)$, medical units $(n=5)$, neu-
\end{abstract}

Corresponding author: Gianfranco Beghi, Santo Stefano Rehabilitation Institute, c/o Ospedale Carlo Mira, Via Anselmo Dall'Orto 99, 27022 Casorate Primo (PV), Italy. E-mail: gianfranco.beghi@sstefano.it

Key words: Observational study; hospital acquired pneumonia; severe acquired brain injury; rehabilitation.

Received for publication: 4 October 2017

Accepted for publication: 30 April 2018

(C) Copyright G. Beghi et al., 2018

Tipografia PI-ME Editrice, Italy

Monaldi Archives for Chest Disease 2018; 88:888

doi: 10.4081/monaldi.2018.888

This article is distributed under the terms of the Creative Commons Attribution Noncommercial License (by-nc 4.0) which permits any noncommercial use, distribution, and reproduction in any medium, provided the original author(s) and source are credited. rosurgery ( $n=3)$ and surgical units $(n=1)$. The aetiology of hospital admission was haemorrhagic in $36 \%$ of cases, traumatic in $36 \%$, anoxic in $13.1 \%$, infectious in $6.5 \%$, ischaemic in $4.9 \%$, and other causes in $3.2 \%$. Among the patients, $93.44 \%$ had received antibiotic therapy in their unit of provenance, and in $61.27 \%$ of cases a multidrug resistant (MDR) bacterium was isolated. On enrolment, 26 patients presented respiratory insufficiency, 29 subjects were in oxygen therapy, and 4 under invasive mechanical ventilation. There were 54 tracheostomized patients, 33 patients with percutaneous endoscopic gastrostomy (PEG) tubes, and 23 with nasogastric (NG) tubes. In 2015, among these subjects admitted to neurological rehabilitation, the incidence of HAP was $13.1 \%$. For these 8 pneumonia cases, it was possible to isolate the bacterium in $62.5 \%$ of cases, and the detected microorganisms were K. pneumoniae $(\mathrm{n}=2)$, P. aeruginosa $(\mathrm{n}=1)$, P. mirabilis $(\mathrm{n}=1)$, S. maltophilia $(\mathrm{n}=1)$, E. cloacae $+\operatorname{MRSCoN}(\mathrm{n}=1)$. Compared to the literature data, the results of the first year of monitoring show a slight increase in HAP cases (13.1\%) in severe brain injury patients on first admission to neurological rehabilitation. These preliminary results need to be further confirmed and monitored over time. The findings moreover confirm the criticality and complexity of care for these patients admitted to neurological rehabilitation units.

\section{Introduction}

Nosocomial or hospital acquired pneumonia (HAP) is an infection contracted during hospital stays, generally with onset $48 \mathrm{~h}$ or more after admission or within 14 days of discharge, that was not already present or in incubation at the time of entering hospital [1-7]. HAP, with an incidence of $15-20 \%$, is the second leading type of nosocomial infection after urinary tract infections $[1,2,4]$. It is one of the causes of death due to hospital infections and one of the leading causes of death in patients hospitalized in intensive care [1,4]. The most critical risk factors are mechanical ventilation $>48 \mathrm{~h}$ (HAP incidence: $9-40 \%$ ), duration of hospital stay, severity of the underlying pathology, APACHE score, and presence of coexistent pathologies [7].

Among patients with stroke, pneumonia is one of the most common respiratory complications, affecting between $5 \%$ and $9 \%$ of patients [8-9], while its frequency is much higher, $21 \%$, among subjects admitted to neurological intensive care units (NICUs) [10-11]. For patients with severe brain injury the frequency of pneumonia as a complication becomes even higher, affecting around $60 \%$ of subjects, owing to prolonged periods in the prone position with attendant risk of inhalation of gastric contents [12].

HAP is divided into the subgroups of ventilator-associated pneumonia (VAP), accounting for $86 \%$ of hospital pneumonia cases [5] and 
stroke-associated pneumonia (SAP). SAP cases are classified as earlyonset (within 5 days of admission, often within 48 hours of the stroke), late-onset (more than 5 days after admission), and chemical aspiration and infectious ones [13]. This last group accounts for 10-50\% nosocomial pneumonia cases and comprises: 1) chemical aspiration pneumonitis - Mendelson's syndrome, 2) aspiration pneumonia and 3) other clinical aspiration syndromes [13]. The current incidence of VAP is estimated at between $9 \%$ and $27 \%$ of all intubated patients [14] and ranges from 2 to 16 episodes per 1000 days of ventilation. The longer the duration of the ventilation, the higher the risk of infection, with an attributable mortality of between $3 \%$ and $30 \%$ [14-15]. The incidence of VAP in patients with severe brain injury is high, with a frequency ranging from $30 \%$ to $50 \%$ of cases [14, 16-17]. SAP is implicated in increases in morbidity and mortality, and in the rise in health care costs. The annual cost of SAP in the US is estimated at approximately 459 million dollars [18]. The incidence of SAP in NICUs is approximately 4.1-56.6\%, in medical intensive care units (MICUs) it is $17-50 \%$, in stroke units $3.9-44 \%$ and in rehabilitation it is $3.2-11 \%$ [18], whereas in intensive rehabilitation following severe cranial trauma, the reported frequency of HAP is $12 \%$ [19].

The term "severe acquired brain injury" (sABI) means a brain injury resulting from head trauma or other causes (cerebral anoxia, haemorrhage, etc.) that causes a condition of coma - Glasgow Coma Scale $(\mathrm{GCS})=/<8$ for more than $24 \mathrm{~h}$ - and sensory-motor, cognitive or behavioural impairments entailing a severe disability [20].

The present observational prospective cohort study evaluates, in patients with sABI on first admission to the specialist intensive rehabilitation unit in Fontanellato (province of Parma) and Porto Potenza Picena (province of Macerata, Italy) the frequency of HAP and its impact on patient outcomes and on complexity of care. It includes subjects admitted starting from 1 January 2015 and discharged within 31 December 2015.

As a secondary endpoint, we also evaluate the antibiotic treatments used and the microbiological data of the infections. We moreover attempt to assess the impact of the pneumonia on the hospitalization, in terms of prolonged duration and possible complications. Finally, we compare the evaluation scores of patients with HAP to those of the subjects who did not present pneumonia, but were admitted with the same pathologies, to evaluate possible variations.

\section{Materials and Methods}

The prospective study enrolled, during the year 2015, and following the informed consent of the patient and/or relatives, all consecutive patients with sABI coming from acute injury units who were being admitted for the first time to the Santo Stefano Rehabilitation Institute of Fontanellato and Porto Potenza Picena (Italy) and who did not present HAP on admission.

We subsequently separated the group that developed HAP during the stay in the rehabilitation unit from the patients with the same admission pathology but who did not develop pneumonia, using the latter as the control group. The patients suspected of HAP presented malaise, fever, chills, stiffness, cough, dyspnoea, chest pain, increased heart and/or respiratory rate or altered respiratory parameters, such as increased purulent secretions or a worsening of hypoxaemia. To diagnose the HAP, patients underwent examinations such as chest X-ray, where possible, micro bronchoalveolar lavage (BAL), bronchial aspirate (BA), haemoculture and haematochemical tests such as complete blood count, procalcitonin and C-reactive protein (CRP). All consecutive patients were enrolled, of either sex, and of any age or nationality; for each subject we recorded the unit of provenance, the date of onset of the acute event, and the date of admission to rehabilitation. The term "severe brain injury" denotes: a cerebral pathology of any type, presenting with an initial period of coma (with GCS $=/<8$ ) lasting more than $24 \mathrm{~h}[20]$.

The collected data also included whether the patient had received antibiotic treatment at the previous unit, and whether any multi-drug resistance (MDR) bacteria were isolated. The dominant pathology and all other comorbidities of the patient were recorded, to obtain an exhaustive picture of the illnesses in progress and any pre-existing ones. We further recorded whether the patient, upon admission to and discharge from the rehabilitation unit, presented respiratory insufficiency, was undergoing invasive or non-invasive mechanical ventilation, had a tracheotomy, was receiving oxygen therapy, carried a percutaneous endoscopic gastrostomy (PEG) or nasogastric (NG) tube, or suffered from critical illness neuropathy. The patient's condition (bedridden, able to sit, or able to stand) at the onset of pneumonia was recorded, along with the date of onset of the pneumonia, its type (HAP, SAP or VAP) and extent (monolateral or bilateral). We also noted whether the pneumonia was connected to difficulties in swallowing and hence of $a b$ ingestis origin. The antibiotic therapy used for the infection was noted, including any changes made in cases of non-success, and the duration of each antibiotic treatment. We recorded the number of days when rehabilitation exercises were skipped, the duration of the hospital stay in days, and the manner in which the patient was discharged: normally discharged, transferred to acute unit due to complications linked to pneumonia, or deceased in the rehabilitation unit or in the acute unit to which the patient was transferred. For the pneumonia cases, we recorded the microbiological data obtained from the culture tests (microBAL, BA and haemoculture), the haematochemical data, if available, at the onset and resolution of the pneumonia such as CRP, procalcitonin (PCT) and white blood cell (WBC). Finally, we noted the scores on the various scales selected for evaluating the patient's activity, participation and quality of life, such as Levels of Cognitive Functioning (LCF) [21-23], Disability Rating Scale (DRS) [22-29] and Barthel Index [30-34].

The Operating Units apply protocols drawn up by the Hospital Infection Committee (HIC) setting out all the recommendations to follow to prevent infections during hospital stays, including pneumonia.

To this end, all measures for preventing infections are put into effect, such as managing contacts and isolation of the patient, where necessary, respiratory physiotherapy manoeuvres aimed at preventing stagnation of bronchial secretions, management of the tracheal tube and of pulmonary ventilators. Moreover, another HIC protocol is adopted for treating the infections themselves, with criteria for deciding whether to start a therapy, how to select an empirical therapy

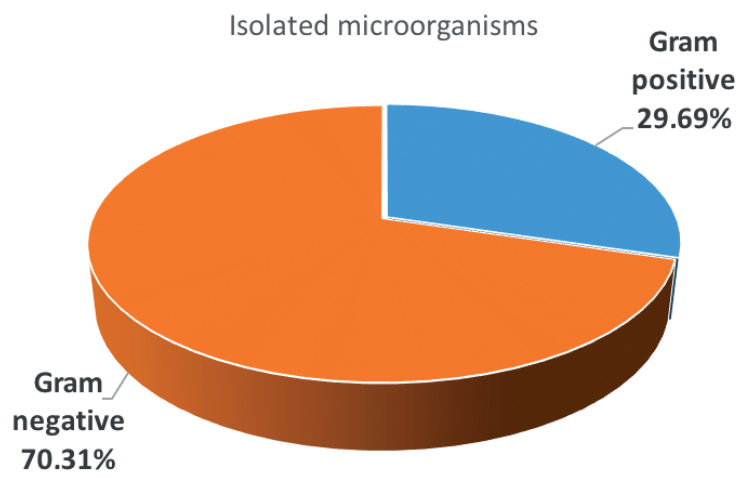

Figure 1. Isolated microorganisms. 
while awaiting culture results, how to monitor the progress of therapies and how to decide whether to suspend or modify them, monotherapy $v s$ polytherapy.

\section{Results}

From 1 January to 31 December 2015, we followed 61 consecutive patients admitted to the specialist unit for severe brain injury of the Cardinal Ferrari Centre of Fontanellato and to the sub-intensive rehabilitation unit for severe acquired brain injury of the Santo Stefano Rehabilitation Institute of Porto Potenza Picena: 39 males and 22 females, average age 59.5 years, coming from critical care $(n=52)$, medical units $(n=5)$, neurosurgery $(n=3)$ and surgical units $(n=1)$ (Table 1). Of the 61 admitted patients, 57 subjects (93.44\%) had received antibiotic therapy in the unit of provenance, and the transfer letter reported isolation of an MDR bacterium in 40 cases (61.27\%).

The microbiological data provided in the letters of transfer to rehabilitation indicated a prior isolation of 64 microorganisms, of which 19 Gram-positive (29.69\%) and 45 Gram-negative (70.31\%). In detail, the most commonly isolated bacteria were Klebisella pneumoniae (16 patients), Pseudomonas aeruginosa (12 patients), Methicillin-Resistant Staphylococcus aureus (MRSA) (9 patients), Escherichia coli (6 patients), Acinetobacter baumannii (5 patients) (Table 2). All the reported bacterial exhibited MDR. The causes which led to hospitalization are reported in Table 3 . The clinical conditions of the subjects on arriving at the rehabilitation unit are reported in Table 4. Although the average age of patients was not high (50.2 years), numerous subjects presented comorbidities (Table 5).
During 2015, among subjects admitted to the intensive neurological rehabilitation units, the incidence of HAP was $13.1 \%$, affecting 8 of the 61 admitted patients. Only 1 pneumonia case was tied to invasive mechanical ventilation (IMV) and all presented with monolateral extent; in addition, 1 of the pneumonia cases was linked to ab ingestis problems (12.5\%). The patients who presented pneumonia were bedridden ( 7 patients), able to sit ( 7 patients), and able to stand ( 3 patients). The following antibiotics were used as anti-infective therapy: piperacilllin/tazobactam (1 patient), meropenem + gentamicin (4 patients), meropenem + levofloxacin (1 patient), meropenem + linezolid (1 patient) and finally meropenem + gentamicin + linezolid + colistin + tigecycline (1 patient). Out of the 8 pneumonia cases, it was possible to isolate the bacteria in 6 subjects (75\% of cases) through BA (3 cases) and BAL (3 cases).

The identified microorganisms were $K$. pneumoniae, in 2 patients, $P$. aeruginosa in 1 patient, $P$. mirabilis in 1 patient, $S$. maltophilia in $1 \mathrm{pa}-$ tient, $E$. cloacae + MRSCoN in 1 patient; all the microorganisms presented MDR. The days of skipped rehabilitation exercises for the patients who contracted pneumonia were on average 13.1 (SD \pm 34.64 , min 0 , max 49).The haematochemical tests performed as reference for the infectious process such as CRP, PCT, and WBC showed an improvement in the parameters from onset to the resolution of the pneumonia (Table 6).

With respect to hospital stay duration, the pneumonia prolonged the period spent in the rehabilitation unit by a few days, as reported in Table 7. Analysing the data for the outcomes of the pneumonia group, $75 \%$ of patients were transferred urgently to acute units for complications linked to the pneumonia (4 patients), while another 2 were transferred for other complications. These patients, on resolution of the acute problem, were re-admitted to the rehabilitation units, without

Table 1. Demographic data.

\begin{tabular}{|c|c|c|c|}
\hline & Pneumonia group & Control group & Total \\
\hline No. of patients & 8 & 53 & 61 \\
\hline \multicolumn{4}{|l|}{ Age of patients } \\
\hline Average & 48.5 & 52.5 & 59.5 \\
\hline SD & 41.719 & 50.204 & 3.53 \\
\hline Min & 19 & 17 & 17 \\
\hline $\operatorname{Max}$ & 78 & 88 & 88 \\
\hline \multicolumn{4}{|l|}{ Nationality } \\
\hline 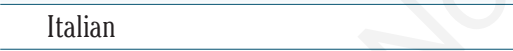 & 8 & 51 & 59 \\
\hline European Union & 0 & 1 & 1 \\
\hline Outside the European Union & 0 & 1 & 1 \\
\hline \multicolumn{4}{|l|}{ Provenance } \\
\hline Intensive Care & 7 & 45 & 52 \\
\hline Neurosurgery & 0 & 3 & 3 \\
\hline Medical Unit & 1 & 4 & 5 \\
\hline Surgical Unit & 0 & 1 & 1 \\
\hline \multicolumn{4}{|l|}{ Prior antibiotic treatment } \\
\hline Yes & 8 & 49 & 57 \\
\hline No & 0 & 3 & 3 \\
\hline N.A. & 0 & 1 & 1 \\
\hline \multicolumn{4}{|l|}{ Prior isolation of MDR bacteria } \\
\hline Yes & 6 & 34 & 40 \\
\hline No & 2 & 18 & 20 \\
\hline N.A. & & 1 & 1 \\
\hline
\end{tabular}

N.A., not available. 
being entered as new cases. The 2 patients discharged normally in any case had an average hospital stay of 217.5 days, which is still less than the average for the subjects who did not contract pneumonia, so clearly the data is not significant owing to the small size of the sample. In the control group, 42 patients (80\%) were discharged normally, 8 subjects were transferred to other units for complications (15.55\%) and finally 3 died during the hospitalization (5.45\%). Note that 1 patient was transferred due to acute clinical problems 8 days after admission to the

Table 2. Microorganisms isolated during hospitalization prior to rehabilitation.

\begin{tabular}{|c|c|c|c|}
\hline & Pneumonia group & Control group & Total \\
\hline Klebsiella pneumoniae & 3 & 13 & 16 \\
\hline Pseudomonas aeruginosa & 0 & 12 & 12 \\
\hline Methicillin-Resistant Staphylococcus aureus (MRSA) & 1 & 8 & 9 \\
\hline Escherichia coli & 1 & 5 & 6 \\
\hline Acinetobacter baumannii & 1 & 4 & 5 \\
\hline Staphylococcus spp Methicillin-Resistant Coagulase Negative (MRCoN) & 0 & 4 & 4 \\
\hline Enterococcus faecalis & 0 & 3 & 3 \\
\hline Serratia marcescens & 0 & 2 & 2 \\
\hline Streptococcus pneumoniae & 2 & 0 & 2 \\
\hline Citrobacter spp. & 0 & 1 & 1 \\
\hline Enterobacter aerogenes & 1 & 0 & 1 \\
\hline Enterococcus faecium & 0 & Na & 1 \\
\hline Haemophilus influenzae & 1 & 0 & 1 \\
\hline Neisseria meningitidis & 1 & 0 & 1 \\
\hline Proteus mirabilis & 0 & 1 & 1 \\
\hline
\end{tabular}

Table 3. Aetiology leading to hospitalisation.

\begin{tabular}{|c|c|c|c|}
\hline & Pneumonia group & Control group & Total \\
\hline Anoxic & 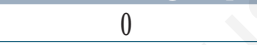 & 8 & 8 \\
\hline Haemorrhagic & 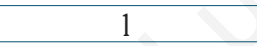 & 21 & 22 \\
\hline Infectious & 1 & 3 & 4 \\
\hline Ischaemic & 2 & 1 & 3 \\
\hline Traumatic & 3 & 19 & 22 \\
\hline Other & 0 & 1 & 1 \\
\hline N.A. & 1 & 1 & 1 \\
\hline
\end{tabular}

N.A., not available.

Table 4. Clinical conditions on admission.

\begin{tabular}{lccc} 
& Pneum no ia group & Control group & Total \\
Respiratory insufficiency & 6 & 20 & 26 \\
\hline Invasive mechanical ventilation & 2 & 2 & 4 \\
\hline Non-invasive mechanical ventilation & 0 & 0 & 0 \\
\hline Oxygen therapy & 5 & 24 & 29 \\
\hline Tracheotomy tube & 8 & 47 & 54 \\
\hline PEG tube & 4 & 29 & 33 \\
\hline NG tube & 5 & 17 & 22 \\
\hline
\end{tabular}

\section{Table 5. Comorbidity.}

\begin{tabular}{llll} 
& Pneumonia group & Control group & \\
Cardiovascular disease & 4 & 20 & 24 \\
\hline Dysmetabolic/Endocrinological disease & 1 & 11 & 12 \\
\hline Neurological disease & 2 & 7 & 9 \\
\hline Respiratory disease & 1 & 6 & 7 \\
\hline Neoplastic disease & 2 & 3 & 5 \\
\hline HCV correlated liver disease & 0 & 4 & 4 \\
\hline Mixed cryoglobulinemia vasculitis & 0 & 2 & 2 \\
\hline Glaucoma & 1 & 0 & 1 \\
\hline Chronic renal insufficiency & 0 & 1 & 1 \\
\hline Venous insufficiency & 0 & 1 & 1 \\
\hline Real lipoma complicated with intestinal invagination & 0 & 1 & 1 \\
\hline Rheumatic disease & 1 & 0 & \\
\hline Psychiatric disease & 0 & 1 & 1 \\
\hline Acute pancreatitis & 0 & 1 & 1 \\
\hline Splenectomy & 0 & 1 & 1 \\
\hline
\end{tabular}


rehabilitation unit, and died at the acute unit where he was transferred.

Table 8 shows, for each of the 2 groups, on admission and discharge, the number of patients with a tracheotomy, PEG or NG tube, which are indicators of complexity and outcomes.

Finally, we report the scores on the various scales employed to evaluate patient activity (LCF), participation (DRS) and quality of life (Barthel Index), subdivided into control and pneumonia groups Table 9).

\section{Conclusions}

The data collected over this first year of observation provides various insights and points for reflection. The first finding is that, compared to the literature data $[18,19]$, there was a slight increase in the number of HAP cases, although this result clearly needs to be further confirmed and monitored in the coming years.

Table 6. Haematochemical tests.

\begin{tabular}{|c|c|c|c|}
\hline & & Values at pneumonia onset & Values at pneumonia resolution \\
\hline \multirow[t]{4}{*}{ C-reactive protein (CRP) mg/dl } & Average & 43.01 & 14.17 \\
\hline & $\mathrm{SD} \pm$ & 60.514 & 42.603 \\
\hline & Min & 0.22 & 1.15 \\
\hline & $\operatorname{Max}$ & 85.8 & 61.4 \\
\hline \multirow[t]{4}{*}{ Procalcitonin (PCT) mcg/L } & Average & 28.2 & 0.34 \\
\hline & $\mathrm{SD} \pm$ & 39.852 & 0.431 \\
\hline & Min & 0.02 & 0.04 \\
\hline & Max & 56.38 & 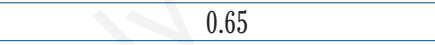 \\
\hline \multirow[t]{4}{*}{ White blood cell (WBC) 1000/mm³ } & Average & 18.845 & $\sqrt{2+2}$ \\
\hline & $\mathrm{SD} \pm$ & 15.492 & 3.217 \\
\hline & Min & 7.89 & 5.17 \\
\hline & Max & 29.8 & 9.72 \\
\hline
\end{tabular}

Table 7. Hospital stay duration.

\begin{tabular}{llccc} 
& & \multicolumn{2}{c}{ Control group } \\
Days at hospital & Average & 142 & 129 \\
\cline { 2 - 5 } & SD \pm & 172.534 & 173.94 & 6 \\
\cline { 2 - 6 } & Min & 20 & 252 & \\
\cline { 2 - 6 } & Max & 264 & 252 & \\
\hline
\end{tabular}

Table 8. Patients with tracheotomy, percutaneous endoscopic gastrostomy (PEG) or nasogastric (NG) tube.

\begin{tabular}{lcc} 
& Admission & \\
Pneumonia group & 7 & 7 \\
\hline Tracheotomy tube & 4 & 3 \\
\hline PEG tube & 5 & 4 \\
\hline NG tube & & \\
Control group & 47 & 18 \\
\hline Tracheotomy tube & 29 & 22 \\
\hline PEG tube & 17 & 2 \\
\hline NG tube & & \\
\hline
\end{tabular}

Table 9. Evaluation scores.

\begin{tabular}{|c|c|c|c|c|}
\hline Scales & $\begin{array}{c}\text { Pneumonia group } \\
\text { admission }\end{array}$ & $\begin{array}{l}\text { Pneumonia group } \\
\text { discharge }\end{array}$ & $\begin{array}{l}\text { Control group } \\
\text { admission }\end{array}$ & $\begin{array}{l}\text { Control group } \\
\text { discharge }\end{array}$ \\
\hline \multicolumn{5}{|c|}{ Levels of Cognitive Functioning (LCF) } \\
\hline Average & 3.5 & 4 & 4.5 & 5 \\
\hline $\mathrm{SD} \pm$ & 2.121 & 2.828 & 3.535 & 4.242 \\
\hline Min & 2 & 2 & 2 & 2 \\
\hline Max & 5 & 6 & 7 & 8 \\
\hline \multicolumn{5}{|c|}{ Disability Rating Scale (DRS) } \\
\hline Average & 21.5 & 20 & 17.6 & 14.5 \\
\hline $\mathrm{SD} \pm$ & 6.363 & 10.606 & 13.576 & 17.677 \\
\hline Min & 18 & 13 & 2 & 2 \\
\hline $\operatorname{Max}$ & 21 & 28 & 26 & 27 \\
\hline \multicolumn{5}{|c|}{ Barthel Index } \\
\hline Average & 10 & 19 & 50 & 66.66 \\
\hline $\mathrm{SD} \pm$ & 14.142 & 26.870 & 70.710 & 57.537 \\
\hline Min & 0 & 0 & 0 & 0 \\
\hline Max & 20 & 38 & 100 & 100 \\
\hline
\end{tabular}


The collaboration with the acute units from which patients were transferred allowed us to map the microorganisms isolated in the patients, confirming the bacterial aetiology, complicated with MDR strains, of the infections that these delicate patients contract during hospital stays, with bacteria that are selected by the repeated antibiotic treatments that such patients undergo. This finding is further confirmed by the microbiological isolations at the onset of HAP, with findings of MDR bacteria that required multiple antibiotic treatments, in the attempt to eradicate them, but which in the majority of cases (75\%) caused a worsening of the patient's condition, with the need to retransfer the subject to the acute unit.

The data collected for the evaluation scales for activity (LCF), participation (DRS) and patient quality of life (Barthel Index) reflects the complexity of patients who enter neurological rehabilitation, and the great effort of the rehabilitation team to achieve significant improvements, although clearly the small sample size does not allow us to assess differences between the functional scales. In this connection, we observed that patients who developed pneumonia were more complicated subjects from a neurological standpoint, although only in 1 case (12.5\%) was the cause attributed to ab ingestis problems, notwithstanding the high percentage of dysphagic subjects in artificial enteric feeding via NG and PEG tubes. Note that, in the literature, the problem of dysphagia in acute patients following stroke affects between $13 \%$ and $94 \%$ of subjects [35] and is responsible for between $17 \%$ and $60 \%$ of respiratory complications in acute settings $[11,12,36]$.

In conclusion, we can say that our study, notwithstanding the small sample size enrolled thus far, allows us to draw some significant conclusions with respect to our primary endpoint (frequency of pneumonia acquired during intensive neurological rehabilitation of severe brain injury subjects), and also with respect to the secondary endpoint (classification of infections and antibiotic therapies employed).

However, it is indispensable to continue the research and increase the sample size, also through multi-centre studies, to be able to evaluate the impact of hospital pneumonia on global patient outcomes, hospital stay durations, and the attendant financial burden, in order to confirm the data also presented by other researchers [37].

\section{References}

1. Mandell GL, Bennett JE, Dolin R. Principles and practices of infection diseases, 6th ed. Churchill Livingstone: 2004.

2. Warrell DA, Cox TM, Firth JD, Benz EJ. The Oxford Textbook of Medicine, 4th ed. Oxford University Press; Oxford: 2003.

3. National Clinical Guideline Centre (UK). Pneumonia: Diagnosis and management of community- and hospital-acquired pneumonia in adult. London: National Institute for Health and Care Excellence (UK); 2014.

4. Kasper DL, Braunwald E, Hauser E, et al. Harrison's Principles of Internal Medicine, 16th ed. McGraw-Hill Inc.; New York: 2004.

5. American Thoracic Society, Infectious Diseases Society of America. Guidelines for the management of adults with hospital-acquired, ventilator-associated, and healthcare associated pneumonia. Am J Respir Crit Care Med 2005;171:388-416.

6. Cunha BA. Nosocomial and healthcare-associated pneumonia. [Internet]. Medscape. Updated June 10, 2014.

7. Blasi F, Gruppo Multidisciplinare FADOI. Attualità nella gestione delle infezioni delle basse vie respiratorie in Medicina Interna. Ital J Med 2010;4:14-41.

8. Finlayson 0, Kapral M, Hall R, et al. Risk factors, inpatient care, and outcomes of pneumoniae after ischemic strokes. Neurology 2011;77:1338-45.
9. Ingeman A, Andersen G, Hundborg HH, et al. In-hospital medical complications, length of stay, and mortality among strokes unit patients. Stroke 2011;42:3214-18.

10. Hilker R, Poetter C, Findeisen N, et al. Nosocomial pneumoniae after acute strokes: implications for neurological intensive care medicine. Stroke 2003;34:975-91.

11. Dziewas R, Ritter M, Schilling M, et al. Pneumonia in acute stroke patients fed by nasogastric tube. J Neurol Neurosurg Psychiatry 2004;75:852-6.

12. Lee K, Rincon F. Pulmonary complications in patients with severe brain injury. Crit Care Res Pract. 2012;2012:207247

13. Buffoni A, Gruppo Multidisciplinare FADOI. Orientamenti terapeutici per il trattamento delle infezioni batteriche nel paziente anziano in Medicia Interna. Ital J Med 2007;1:34-55.

14. Alvarez JML, Perez Quevedo 0, Roldan Furelos L, et al. Pulmonary complications in patients with brain injury. Pulm Res Respir Med Open J 2015;2:69-74.

15. Barbier F, Andremont A, Wolff M, et al. Hospital-acquired pneumonia and ventilator-associated pneumonia: recent advances in epidemiology and management. Curr Opin Pulm Med 2013;19:216-28.

16. Jovanovic B, Milan Z, Markovic-Denic L, et al. Risk factors for ventilator-associated pneumonia in patients with severe traumatic brain injury in a Serbian trauma centre. Intern $\mathrm{J}$ Infect Dis 2015;38:46-51.

17. Zygun DA, Zuege DJ, Boiteau PJ, et al. Ventilator-associated pneumonia in severe traumatic brain injury. Neurocrit Care 2006;5:108-14.

18. Hannawi Y, Hannawi B, Rao C, et al. Stroke-associated pneumonia: major advances and obstacles. Cerebrovasc Dis 2013;35:430-43.

19. Hansen TS, Larsen K, Engberg AW. The association of functional oral intake and pneumonia in patients with severe traumatic brain injury. Arch Phys Med Rehabil 2008;89:2114-20.

20. De Tanti A, Zampolini M, Pregno S, CC3 Group. Recommendations for clinical practice and research in Severe Brain Injury in intensive rehabilitation: the Italian Consensus Conference. Eur J Phys Rehabil Med 2015;51:89-103.

21. Hagen C, Malkmus D, Durham P. Cognitive assessment and goal setting. In Rehabilitation of the head injured adult: comprehensive management. Downey Ca: professional staff association of Rancho Los Amigos Hospital, Inc.: 1979.

22. Gouvier WD, Blanton PD, LaPorte KK, et al. Reliability and validity of the disability rating scale and the levels of cognitive functioning scale in monitoring recovery from severe head injury. Arch Phys Med Rehabil 1987;68:94-97.

23. Formisano R, Bivona U, Penta F, et al. Early clinical predictive factors during coma recovery. Acta Neurochir Suppl 2005;93:201-5.

24. Rappaport M, Hall KM, Hopkins K, et al. Disability rating scale for severe head trauma: coma to community. Arch Phys Med Rehabil 1982;63:118-23.

25. Eliason M, Topp B. Predictive validity of Rappaport's Disability Rating Scale in subjects with acute brain dysfunction. Phys Ther 1984;64 1357-61.

26. Hall KM, Cope DN, Rappaport M. Glasgow Outcome Scale and Disability Rating Scale: comparative usefulness in following recovery in traumatic head injury. Arch Phys Med Rehabil 1985;66:35-7.

27. Hall KM, Hamilton BB, Gordon WA, et al. Characteristics and comparisons of functional Assessment indices: Disability rating scale, functional independence measure and functional assessment measure. J Head Trauma Rehabil 1993;8:60-74. 
28. Fleming JM, Thy B0, Maas F. Prognosis of rehabilitation outcome in head injury using Disability Rating Scale. Arch Phys Med Rehabil 1994;75:156-63.

29. Hall KM, Mann N, High W, et al. Functional measures after traumatic brain injury: ceiling effects of FIM, FIM+FAM, DRS and CIQ. J Head Trauma Rehabil 1996;11:27-39.

30. Shah S, Vanclay F, Cooper B. Improving the sensitivity of the Barthel Index for stroke rehabilitation. J Clin Epidemiol 1989;42:703-9.

31. Mahoney FL, Barthel DW. Functional evaluation: the Barthel Index. Maryland State Med J 1965;14:61-5.

32. Wade DT, Collin C. The Barthel ADL index: a standard measure of physical disability? Int Disabil Stud 1988;11;89-92.
33. Ng YS, Chua KS. States of severely altered consciousness: clinical characteristics, medical complications and functional outcome after rehabilitation. NeuroRehabilitation 2005;20:97-105.

34. Shah S, Muncer SJl. A comparison of rehabilitation outcome measures for traumatic brain injury. OTJR 2003;23:2-9.

35. Langdon C. Dysphagia and respiratory infections. In: Acute Ischemic Stroke, JC Garcia Rodriguez (Editor). InTech Online; 2012: p. 79-100.

36. Brogan E, Langdon C, Brookes K, et al. Respiratory infections in acute stroke: nasogastric tubes and immobility are stronger predictors than dysphagia. Dysphagia 2014;29:340-5.

37. Pistoia F, Sacco S, Franceschini M, et al. Comorbidities: a key issue in patients with disorders of consciousness. J Neurotrauma 2015;32:682-8. 